sinusitis almost life-long. In the present case severe pyorrhoea, tonsillitis and an axillary abscess occurred during the three years preceding the patient's death, nothing being known of her previous history.

There seems a possibility that chronic ocular conditions which fail to react to treatment may in some cases be associated with an altered blood picture a study of which may materially modify the line of treatment and also the prognosis.

In view of the recent suggestions that the barbiturate group of drugs given alone or in combination with amydopyrin may exert a selective toxic influence upon the marrow elements, more particularly the granulocytes with the production of a primary agranulocytosis, it should be recorded that this patient had from time to time taken veramon (amydopyrin methylbarbiturate) for headache and at the onset of her illness was given this drug once or twice a day for the pain. She had, however, taken a course of theominal (luminal and theobromine) for a period during the previous year without any ill effects.

\title{
SPANISH-ARABIC OPHTHALMOLOGY
}

BY

A. F. MacCallan, C.B.E.

LONDON

To celebrate the International Congress of Ophthalmology held at Madrid last year the well-known firm of Cusi (The Laboratories of the North of Spain), decided to publish a translation of the works of a twelfth-century Spanish-Arabic author. This author is named Mohammad ibn Qassoum ibn Aslam al-Ghafiqi, whose manuscript is treasured in the library of the Escurial, bearing the title "Al-Morchid fi' 1-Kohhl." Very little is known about the author except that he lived at Cordova and practised as an oculist.

The translation of the Arabic original into French was confided to Dr. Max Meyerhof of Cairo, the distinguished medicalorientalist, to whose erudition reference has repeatedly been made in the Brit. Jl. of Ophthal.

A large part of the manuscript is concerned with general medicine and natural philosophy, and it is only the sixth book or chapter which is specially devoted to ophthalmology. Of this the fifth section constitutes the main part of the translation, and for its matter the published work of a celebrated oculist, Ali ibn 'Isa, who practised at Baghdad about. A.D. 1000, has been drawn upon largely by Al-Ghafiqi. 
Dr. Meyerhof's remarks on the collyria in use in the East in ancient times are of great interest. Liquid collyria are only a comparatively recent invention and were quite unknown to the ancients. Also the lack of a stable fatty base prevented the preparation of really good ocular ointments. The old ointments were made up with honey or wax, and sold either in pots or made up into sticks. Descriptions of these are found in the Ebers papyrus, which was copied about B.C. 1650. Ocular cosmetics were known in the Nile valley more than a thousand years before this; they were made of powdered malachite or sulphide of antimony.

The Greeks enriched their ocular therapeutics from the experience of the Egyptians and Babylonians, and, in their turn, transmitted their knowledge to the Romans and Arabs.

Throughout the middle ages the physicians of Europe did not create a single treatise on ophthalmology comparable to those of the Arabic oculists. It was necessary to wait until the beginning of the eighteenth century to find in the works of Saint-Yves, Maitre-Jan and Brisseau any notable progress since the time of the great Arabs.

Some of the Moslem physicians of Spain left records of visits to Baghdad to gain professional knowledge and it may be that our author, Al-Ghafiqi, made this journey.

His observations on cataract, preliminary to operation, are sound, the patient must have good perception of light, the pupil must be active and the general health good.

The patient must have no cough, his bowels should be evacuated and he should gargle for several days before the operation. A venesection may be indicated and his diet carefully ordered.

On the day of operation the wind should be from the north, to avoid the heat and dust storms which are prevalent with a wind from the south, and the day should be sunny since in the Orient cloudy or wet weather makes evervbody feel miserable. These tips Al-Ghafiqi must have learnt in Baghdad.

The description of the operation is as follows:- The patient sits on a cushion. with his knees drawn up against his chest, and his hands clasped round his legs. The operator sits on a low chair in front of the patient. The eye which is not to be operated on is to be lightly bandaged. An assistant stands behind the patient and steadies his head. The right eye is operated on with the left hand and the left eye with the right hand. Pressure is made with the handle of the needle on the sclerotic at the point where it is proposed to insert the instrument; this is done for two reasons, first to accustom the patient to maintain the eye stationary, and second to make a little depression on the sclerotic, so that the needle when entering shall not slip. It must be remem- 
bered that the needle was not very sharp, being made of gilded copper. The needle is then entered at the level of the pupil, or a little higher, at a distance from the corneal margin equal to the length of the spear-headed point of the needle, four or perhaps five millimetres. The needle enters the posterior chamber. At the same time the globe is steadied with the finger and thumb of the free hand.

The needle is entered as far as the pupil or a little farther. Then the patient should be gently encouraged to remain perfectly quiet, while the needle is inclined until it is seen just above the cataract. Then the handle of the needle is raised very slowly, pushing the cataract downwards. If the cataract is at once depressed, the needle should not be removed until it is seen that the cataract does not reassume its original position. If it does the mancuvre must be repeated. The needle is then withdrawn, and both eyes are bandaged.

This is an excellent description of the operation of couching a cataract.

I have seen in Egypt many patients for whom this operation had been done by travelling quacks, generally of Moorish origin. The majority of the patients were already blind as the result of the supervention of glaucoma, but occasionally a permanently good result was seen. The striking factor of the operation is the immediate improvement of the visual acuity, which, however, may be lost quickly as the result of inflammation or more usually as the result of glaucoma.

Al-Ghafiqi describes four kinds of trachoma. The first is a redness of the internal aspect of the eyelid, which is covered by tiny little grains (our stage I of trachoma). This often begins as an acute ophthalmia (a fact which was rediscovered by Morax and Lakah in 1902). The second variety presents a greater roughness of the conjunctiva, and is accompanied by pain and heaviness of the lid (our stage II $a$ ). When the acute ophthalmia has subsided the treatment of the trachoma must be undertaken. In the third variety the roughnesses of the conjunctiva are more pronounced and look like the fissures in an opened fig; here the author intends to describe the marked papillary hypertrophy found in stage II $b$. The fourth variety is more dangerous and more chronic and is associated with trichiasis-entropion (our stage III).

As regards treatment the author prescribes in bad cases mechanical treatment (curettage or brossage) with either sugar or an instrument, and the application of corrosive remedies, in fact, exactly the same treatment as is used at the present time in trachomatous countries for the treatment of one of the stages (IIa) of the disease. 
The operative treatment of chalazion by incision and evacuation of the contents with a curette is correctly described.

The treatment of lacrimal abscess by incision, scraping and probing is recommended as preferable to an expectant treatment.

Some of the prescriptions which Al-Ghafiqi gives contain curious ingredients. For loss of pigment of the eyelashes or canities the receipt is as follows:-Burn snail shells and triturate with the fat of wild goat or bear and with the mixture massage the palpebral borders. Many of the other remedies are equally surprising.

Meyerhof's book, which is called "Le Guide d'Oculistique d'Al-Ghafiqi" is tastefully arrayed in vellum with an Arabic inscription. It is beautifully printed at l'Institut graphique Oliva de Vilanova at Barcelona.

\section{FOCAL INFECTION IN DISEASES OF} THE EYE*

\section{1.-Report of Certain Laboratory Examinations}

BY

Conrad Berens, M.D., Paul T. Connolly, M.D., and GEORGE H. CHAPMAN, B.A.Sc.

NEW YORK

\section{Outline}

1. Introduction.

2. Serological methods.

a. Complement fixation.

b. Agglutination reactions.

c. Intradermal tests.

3. Bacteriological methods.

a. Rough and smooth differentiation.

b. Staphylococci.

c. Enterococci.

$d$. Significance of toxicity and other tests.

* From the Laboratory of the Lighthouse Eye Clinic of the New York Association for the Blind and the Clinical Research Laboratory, New York. Abstract of paper read by title before the Fourteenth International Congress of Ophthalmology, Madrid, April 16-22, 1933

This study was aided by a grant from the Ophthalmological Foundation, Inc. 